INTERNATIONAL JOURNAL OF MULTIDisciplinARY RESEARCH AND ANALYSis

ISSN(print): 2643-9840, ISSN(online): 2643-9875

Volume 04 Issue 11 November 2021

DOI: 10.47191/ijmra/v4-i11-05, Impact Factor: 6.072

Page No.- 1533-1536

\title{
Distal Arch Aneurysm Repair: Hybrid TEVAR a Novel Approach
}

\author{
Prashiddha Bikram Kadel ${ }^{1}$, Uttam Krishna Shrestha ${ }^{2}$, Kajan Raj Shrestha ${ }^{3}$, Dinesh Gurung ${ }^{4}$ \\ 1,2,3,4Vascular Unit, Department of Cardiothoracic Vascular Center, Manmohan Cardiothoracic Vascular and \\ Transplant Center, Maharajgunj, Kathmandu, Nepal
}

\begin{abstract}
Thoracic endovascular aortic reconstruction (TEVAR) is increasingly used in the management of descending aortic pathology including aneurysms, dissections and transaction. When treating aortic arch pathology, hybrid procedures have been devised, in which major arch vessels are bypassed using a variety of techniques. Here we present a case of 48 years male, presented with shortness of breath and chest pain for 2 months. The Contrast enhanced computerized tomogram of chest showed multiple saccular outpouching at distal arch and mid descending aorta. He underwent hybrid procedure bypassing Innominate artery to left carotid and left subclavian artery followed by TEVAR covering the entire saccular aneurysm. His postoperative period was uneventful and is doing well till date.
\end{abstract}

KEYWORDS: Hybrid surgery, Saccular aneurysm, Thoracic aortic aneurysm

\section{INTRODUCTION}

Aneurysm is abnormal dilatation of part of vessel. Aneurysm in its course may thrombose, rupture, enlarge in size and lead to morbidity and mortality. ${ }^{1}$ Hybrid aortic arch replacement comprises translocation of the supra-aortic arteries and endovascular stent deployment across the transverse aortic arch may offer an alternative to open arch replacement. ${ }^{2}$ Thoracic aortic aneurysm is one of the most complicated topic of cardiovascular surgery. It has a dismal progressive course where $40 \%$ will rupture. No effective medical therapy exists so the standard treatment involves open surgical replacement of the aneurysmal aorta. ${ }^{3}$ Its management is challenging as the surgery is complicated. In the recent years with the technological development endovascular surgery has been implemented as an alternate option to open surgery. However endovascular treatment cannot completely surpass the open surgery.

\section{CASE}

A 48 years male presented with complaint of chest pain for 2 months and shortness of breath for 1 week. On physical examination, his blood pressure, pulse rate, respiratory rate were within normal limit. His systemic examination was found to be inconclusive. The patient underwent cardiorespiratory workup which was within normal limit for his age. On the basis of initial complaint and high suspicion the patient underwent Contrast Enhanced Computerized tomogram (CECT) of chest which showed multiple saccular outpouching at distal arch and mid descending aorta (Saccular aneurysm). The size of aneurysm at distal arch was $4 \mathrm{~cm} \times 3 \mathrm{~cm}$ and the aneurysm at mid descending aorta was $7 \mathrm{~cm} \times 6 \mathrm{~cm}$. (Figure 1) There was no contrast leak from the aneurysm hence, he was planned for aneurysmorraphy electively. Under general anesthesia, he underwent carotico-carotid and left caroticosubclavian bypass using ringed PTFE 7mm tube graft (Figure 2) followed by Thoracic Endovascular Aortic Repair (TEVAR) (Vailant Captivia (C $34 \mathrm{~mm} \times 34 \mathrm{~mm} \times 167 \mathrm{~mm}$ ). The stent graft landed proximally on zone 1 just distal to innominate artery covering left carotid and left subclavian artery and distally in the mid thoracic aorta. The left subclavian artery stump was plugged using $8 \mathrm{~mm}$ amplatz device. After the procedure he was extubated without inotropic support. His postoperative period was uneventful and was discharged on $5^{\text {th }}$ postoperative day without undue complications. Till his last follow up, no complication per se stent graft and bypass has been noted.

\section{DISCUSSION}

Aortic aneurysm may present with vast clinical settings and as a complication may rupture in due course of time. After rupture it is associated with high mortality and morbidity. In the past open surgery was the only option for the treatment of thoracic 


\section{Distal Arch Aneurysm Repair: Hybrid TEVAR a Novel Approach}

aneurysm. However, the trend is moving towards endovascular surgery which is safer in properly selected patient. ${ }^{4}$ Use of endovascular treatment is ever increasing with higher technical success rates with reduced mortality and morbidity. With new technique and methods, the mortality of open surgery has also decreased to $2-3 \% .^{5}$ However open surgery with associated morbidity is more present in old age and patient with comorbidities. In case of contraindication to surgery, the option can always be either endovascular or hybrid procedure. Indication for both TEVAR and open surgery is similar when aneurysm involves the distal arch there is chance of occlusion of left subclavian artery and left carotid artery if landing zones are not clear. Limitation of both open surgery and TEVAR is felt when there in involvement of left subclavian artery by aneurysm. Involvement of upto $40 \%$ left subclavian artery in case of TEVAR performed for thoracic artery aneurysm, the reported incidence of arm, spinal cord and vertebrobasilar ischemia was $6 \%, 4 \%$ and $2 \%$, respectively. ${ }^{6}$ Those patients also had $5 \%$ risk for anterior circulation stroke and $6 \%$ for death. So revascularization of left subclavian is important, however some surgeons selectively perform Left subclavian artery revascularization only when there is a dominant left vertebral artery $(60 \%)$, a previous left internal mammary coronary artery bypass graft or when the distal right vertebral segment is absent. ${ }^{7}$ In addition to this, when both left subclavian artery and left common carotid artery is involved, an additional complementary surgery is to be performed for the revascularization of the same, this is when hybrid surgery comes into play. With staged hybrid approach for extensive Thoracic abdominal aneurysm combining proximal TEVAR with open surgery for distal thoracic aortic aneurysm is safe and appears to be more effective than the traditional repair with 100 percent success and 0 percent mortality. ${ }^{8}$ It is believed that in some cases TEVAR is better than open surgery in terms of low morbidity and mortality, in this case we performed open surgery in order to provide adequate blood supply to the brain and left arm, there was no additional surgery for the left upper limb in the follow up period with good pulse and function however no definite evidence shows endovascular or hybrid procedure is superior to open surgery. This topic is yet to be explored by the means of randomized controlled trial.

\section{CONCLUSION}

The hybrid approach for the treatment of distal arch aneurysm tends to evolve with increasing role in old patients and patients with comorbidities. These procedures can be performed without the use of cardiopulmonary bypass and with minimal complications. Hybrid procedure can be safely performed with no delayed stroke or endoleak in midterm followup for distal arch aneurysm. Thus these procedures can be opted in selective patients with good immediate and midterm results.

\section{REFERENCES}

1) Townsend CM, Beauchamp RD, Evers BM, Mattox KL. Sabiston textbook of surgery E-book. Elsevier Health Sciences; 2016 Apr 22.

2) Dronavalli VB, Loubani M, Riley $P$, Bonser RS. Failure to exclude a saccular arch aneurysm during hybrid repair: arch replacement without cerebral circulatory arrest. Interactivecardiovascular and thoracic surgery. 2009 Oct 1;9(4):677-9. https://doi.org/10.1510/icvts.2009.208413

3) Rupture- Crawford ES, DeNatale RW. Thoracoabdominal aortic aneurysm: observations regarding the natural course of the disease. J Vasc Surg. 1986; 3(4):578-82. [PubMed: 3959256] https://doi.org/10.1016/0741-5214(86)90281-8

4) Nienaber $C A$, Fattori $R$, Lund $G$, et al. Nonsurgicalreconstruction of thoracic aortic dissection by stent-graftplacement. N Engl J Med 1999;340(20):1539-45. DOI: 10.1056/NEJM199905203402003

5) Svensson LG, Crawford ES, Hess KR, Coselli JS, Safi HJ.Experience with 1509 patients undergoing thora-coabdominal aortic operations. J Vasc Surg 1993;17(2):357-68 https://doi.org/10.1016/0741-5214(93)90421-H

6) Feezor RJ, Martin TD, Hess PJ, et al. Risk factors forperioperative stroke during thoracic endovascular aorticrepairs (TEVAR). J Endovasc Ther 2007;14(4):568-73 https://doi.org/10.1177/152660280701400420

7) Rizvi AZ, Murad MH, Fairman RM, Erwin PJ, Montori VM.The effect of left subclavian artery coverage on morbidityand mortality in patients undergoing endovascularthoracic aortic interventions: a systematic review and meta-analysis. J Vasc Surg 2009;50(5):1159-69 https://doi.org/10.1016/j.jvs.2009.09.002

8) Johnston WF, Upchurch Jr GR, Tracci MC, Cherry KJ,Ailawadi G, Kern JA. Staged hybrid approach using proximal thoracic endovascular aneurysm repair and distal open repair for the treatment of extensive thoracoabdominal aortic aneurysms. J Vasc Surg 2012[Epub, Jul 24 DOI: 10.1055/s-0040-1715881 
Distal Arch Aneurysm Repair: Hybrid TEVAR a Novel Approach

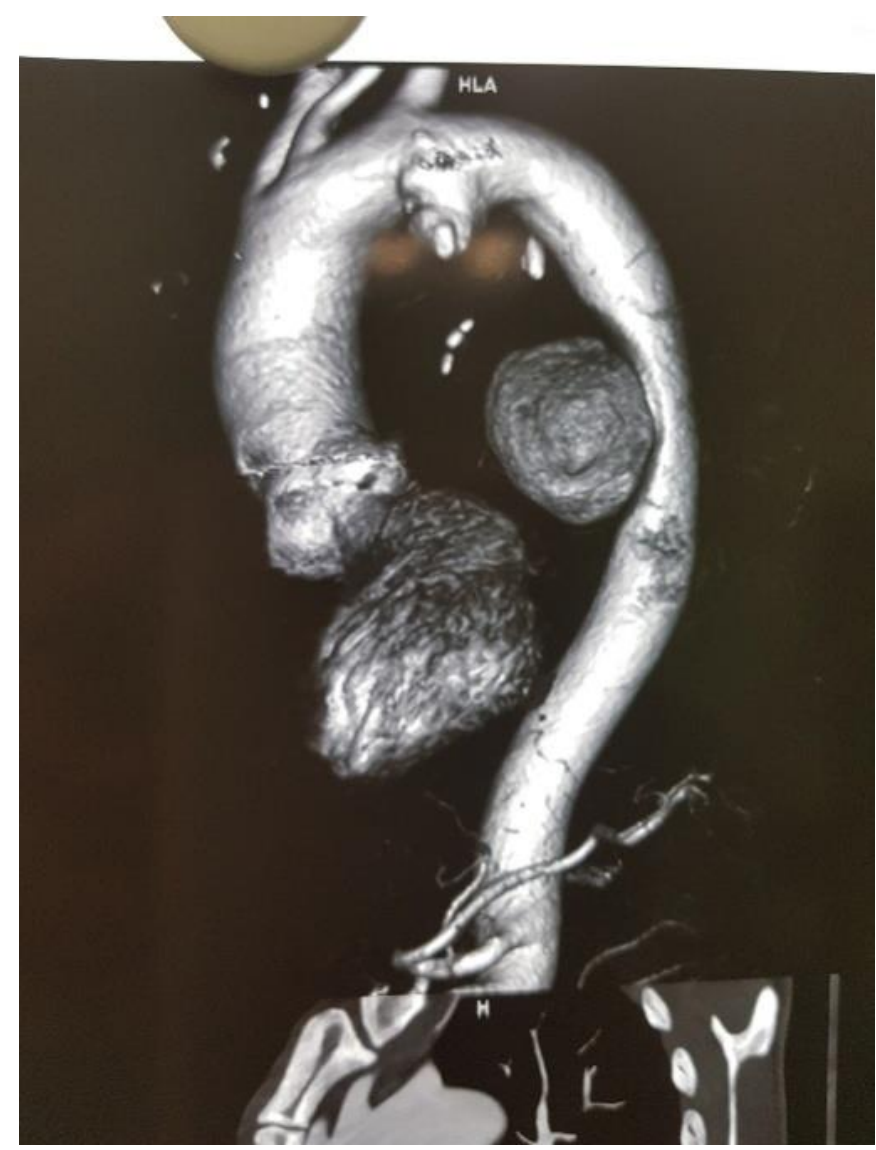

Figure 1: Saccular aneurysm of distal aortic arch and thoracic abdominal aorta

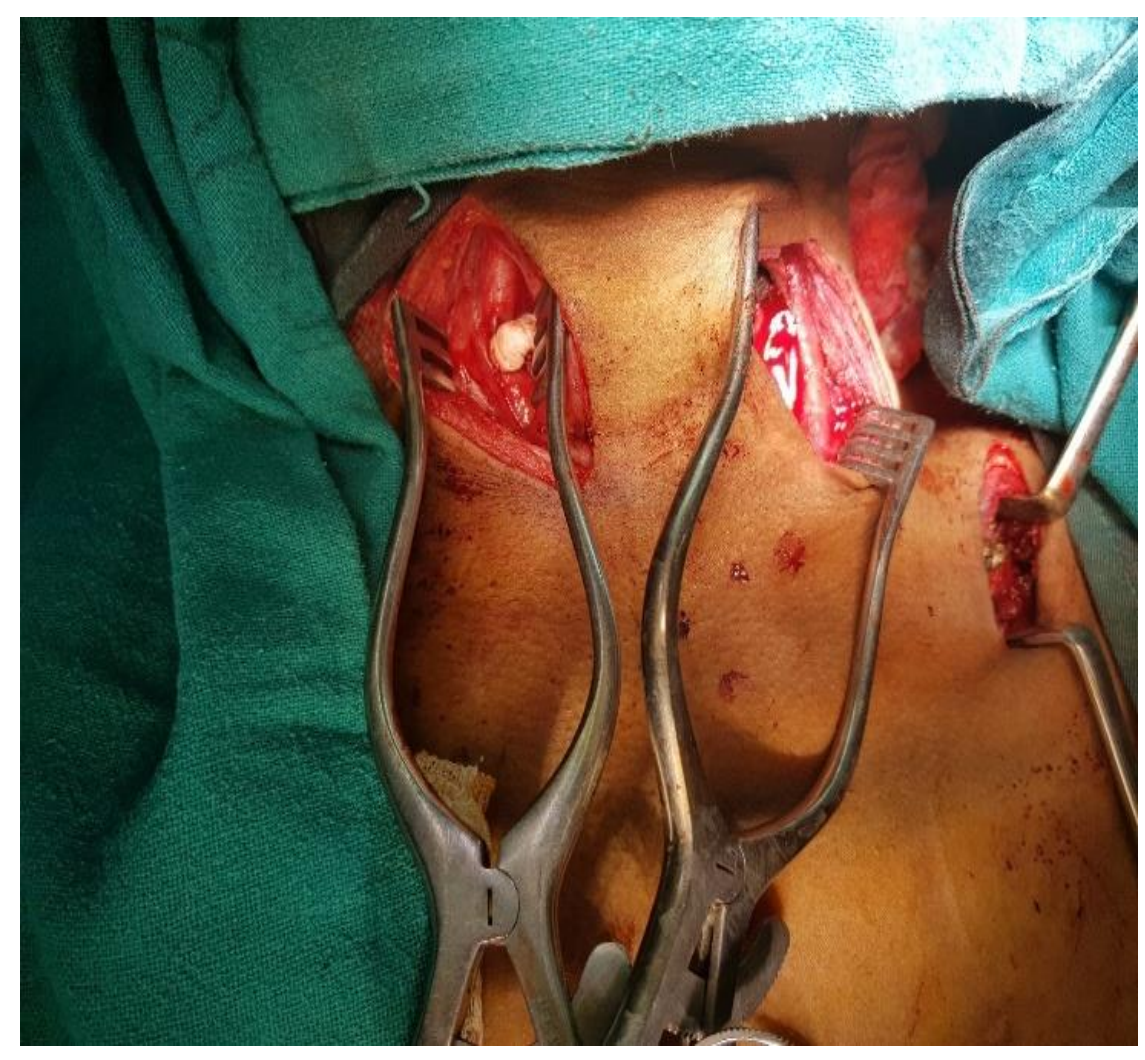

Figure 2: left Carotico-subclavian bypass 
Distal Arch Aneurysm Repair: Hybrid TEVAR a Novel Approach

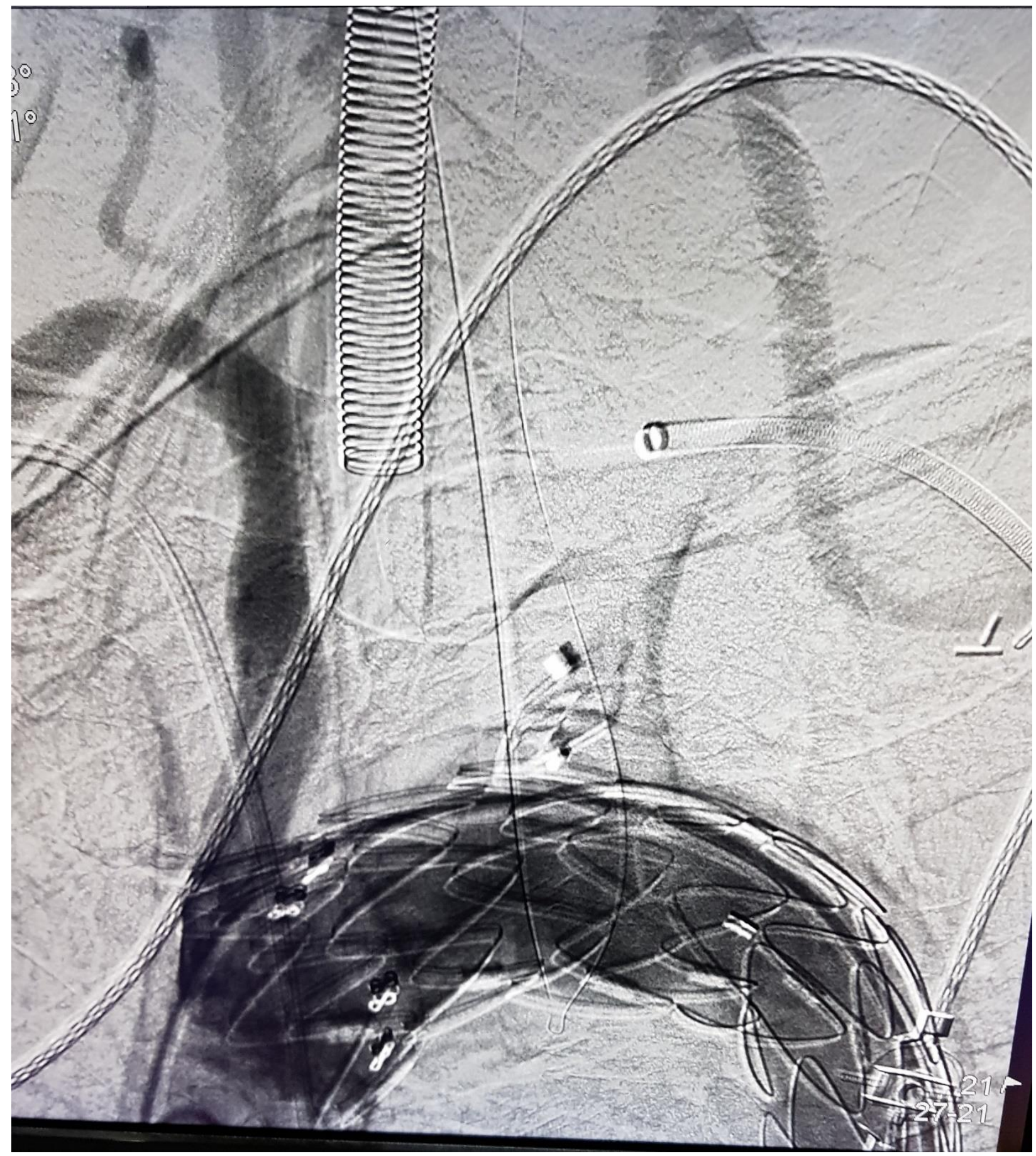

Figure 3: successful deployment of endovascular stent with good flow in left subclavian artery via right common carotid artery 